\title{
Food loss and Waste Reduction as an Integral Part of a Circular Economy
}

\author{
Maria Virginia Vilariño ${ }^{1 *}$, Carol Franco ${ }^{2}$ and Caitlin Quarrington ${ }^{3}$ \\ ${ }^{1}$ Argentinean Business Council for Sustainable Development, Buenos Aires, Argentina, ${ }^{2}$ Forest Resources and Environmental \\ Conservation, Virginia Tech University, Blacksburg, VA, USA, ${ }^{3}$ MindFuel (Science Alberta Foundation), Calgary, AB, Canada
}

\section{OPEN ACCESS}

Edited by:

S. Venkata Mohan,

Indian Institute of Chemical

Technology (CSIR), India

Reviewed by:

Deepak Pant

Flemish Institute for Technological Research (VITO), Belgium

Nastaein Qamaruz Zaman,

Universiti Sains Malaysia, Malaysia

*Correspondence:

Maria Virginia Vilariño mvilarino@ceads.org.ar

Specialty section:

This article was submitted to Wastewater Management,

a section of the journal

Frontiers in Environmental Science

Received: 31 January 2017

Accepted: 25 April 2017

Published: 17 May 2017

Citation:

Vilariño MV, Franco C and Quarrington C (2017) Food loss and Waste Reduction as an Integral Part of

a Circular Economy.

Front. Environ. Sci. 5:21. doi: 10.3389/fenvs.2017.00021
One-third of food produced for human consumption is lost or wasted globally, which amounts to about 1.3 billion tons per year. An updated review of global food loss and waste (FLW) is presented, as well as the related environmental, social and economic impacts, based on existing data and peer-reviewed literature. The authors reflect on the different food waste patterns and challenges faced by diverse regions around the world. The scale of FLW throughout the food value chain is analyzed, from agricultural production down to household consumption and disposal. FLW represent a waste of resources used in each production stage, such as land, water and energy; FLW also contributes to unnecessary increase of greenhouse gas (GHG) emissions. The environmental and socio-economic impacts of FLW are analyzed based on reviewed life cycle assessments. Providing insights into key concepts around FLW, this article highlights the scale of the problem at a global and regional level. It also reflects on the main challenges for implementing strategies to reduce FLW and the implications for policy-making.

Keywords: food loss and waste, FLW, circular economy, life cycle assessment, sustainable waste management practices, sustainability, socio-economic impacts

\section{INTRODUCTION AND DEFINITIONS}

The terms "food loss" and "food waste" are commonly used to describe total losses and waste within the different steps of the food supply chain (FSC) - production, postharvest, processing, distribution and consumption. However, there is no single definition of food loss and waste (FLW). Various actors and stakeholders in global food systems use many definitions and terminologies (Buzby et al., 2015; Food and Agriculture Organization, 2015). Coupled with this disparity is international inconsistency with accounting frameworks, due to different goals for quantifying FLW. According to Chaboud and Benoit (2017), variances in defining FLW occur in terms of scope (intended for human consumption or not), timing (pre-harvested, ready for harvest, post-harvest), criterion (utilization, edibility or nutrition), perspective (environmental, social, food security), and type (qualitative or quantitative).

In this context, FAO's "Global Initiative on FLW Reduction" offers a definition as a global reference to be used by any stakeholder within the context of their operations. Food loss is defined by Food and Agriculture Organization (2014) as the decrease in mass or quality attributes of food throughout the FSC. As defined by FAO, food waste is part of food loss but decides to continue using the term "food loss and waste" to emphasize the waste component of food loss, its distinct drivers and solutions.

The Food Loss and Waste Protocol (FLW Protocol), a global multi-stakeholder partnership, gives globally consistent definitions to define, measure and report FLW in relation to specific goals 
of stakeholders (e.g., businesses, NGOs, etc.; Hanson et al., 2016; Chaboud and Benoit, 2017). FLW protocol defines FLW as "the weight of food and/or associated inedible parts removed from the food supply chain" (Hanson et al., 2016). Food losses (FL) refer to the decrease in edible food mass that takes place at production, post-harvest and processing stages in the FSC, before it reaches the consumer. Food waste (FW) refers to food that is of good quality and fit for human consumption but that does not get consumed because it is discarded at the end of the food chain (distribution and consumption; Parfitt et al., 2010; Lipinski et al., 2013).

\section{STATE AND TRENDS OF GLOBAL FLW}

According to (Food and Agriculture Organization, 2011), a third, by weight, of all food produced in the world gets lost or wasted globally. This equates to approximately 1.3 billion tons per year ${ }^{1}$. When converted into calories, global FLW amounts to approximately $24 \%$ of all food produced, equivalent to $614 \mathrm{kcal} / \mathrm{cap} /$ day (Kummu et al., 2012; Food and Agriculture Organization, 2013). Although the waste estimates provided have many uncertainties, they are the most comprehensive global numbers currently available (Lipinski et al., 2013).

FLW can occur at every stage of the food value chain, from initial agricultural production down to final household consumption (Parfitt et al., 2010; Gustavsson et al., 2011; Kummu et al., 2012). Production stage represents $24-30 \%$ of global FLW, while post-harvest stage accounts for $20 \%$ and consumption for 30-35\% (Kummu et al., 2012; Lipinski et al., 2013).

Regarding the type of food commodities that are being lost globally, statistics depend on whether FLW is measured in terms of calories or weight. On a caloric basis, cereals comprise the largest share of global FLW (53\%), followed by roots and tubers (14\%), and fruits and vegetables (13\%). Meat comprises a relatively small share-though not in terms of environmental impacts-at 7\% (Food and Agriculture Organization, 2011). However, on a weight basis, fruits and vegetables are the largest source of FLW (44\%), followed by roots and tubers (20\%).

If we consider the rate of FLW over each commodity production, $20-22 \%$ of total produced cereals are lost, compared to $39-44 \%$ of fruits and vegetables, $33 \%$ of roots and tubers (Kummu et al., 2012) ${ }^{2}$ and $24 \%$ of seafood (Lipinski et al., 2013) ${ }^{3}$.

\section{REGIONAL CHARACTERIZATION OF FLW ALONG THE FOOD CHAIN}

The amount of FLW in developed and developing countries is roughly the same, amounting to 670 and 630 million tons respectively (Food and Agriculture Organization, 2015). However, they differ on a per capita basis: $257 \mathrm{~kg} / \mathrm{year}$ for countries in developed countries compared to $157 \mathrm{~kg} /$ year in developing countries, on a weigh basis (Gustavsson et al., 2011).

\footnotetext{
${ }^{1}$ Estimated by FAO for 2009

${ }^{2}$ FLW averaged over the years 2005-2007

${ }^{3}$ FLW in 2009
}

Figure 1A shows regional differences also on a caloric per capita basis.

The rate of FLW out of total food produced is very similar in developed and developing countries (Kummu et al., 2012; Shafiee-Jood and Cai, 2016; See Figure 1B).

Furthermore, the pattern and causes of FLW along the FSC also differs among regions. In medium- and high-income countries, over half of the FLW occur in distribution and consumption level (Shafiee-Jood and Cai, 2016; Chaboud and Benoit, 2017), meaning that it is discarded even if it is still suitable for human consumption. In low-income countries, food is lost mostly during the production and post-harvest, mainly due to losses during the handling and storage phase (Food and Agriculture Organization, 2011; Kummu et al., 2012).

\section{ENVIRONMENTAL IMPACTS OF FLW}

Based on reviewed life cycle assessments, FLW represents not only a challenge to improving global food and nutrition security, but also represents a wastefulness of limited natural resources.

The production of these lost and wasted food accounts for $173-250 \mathrm{~km}^{3}$ of water consumption per year (surface and

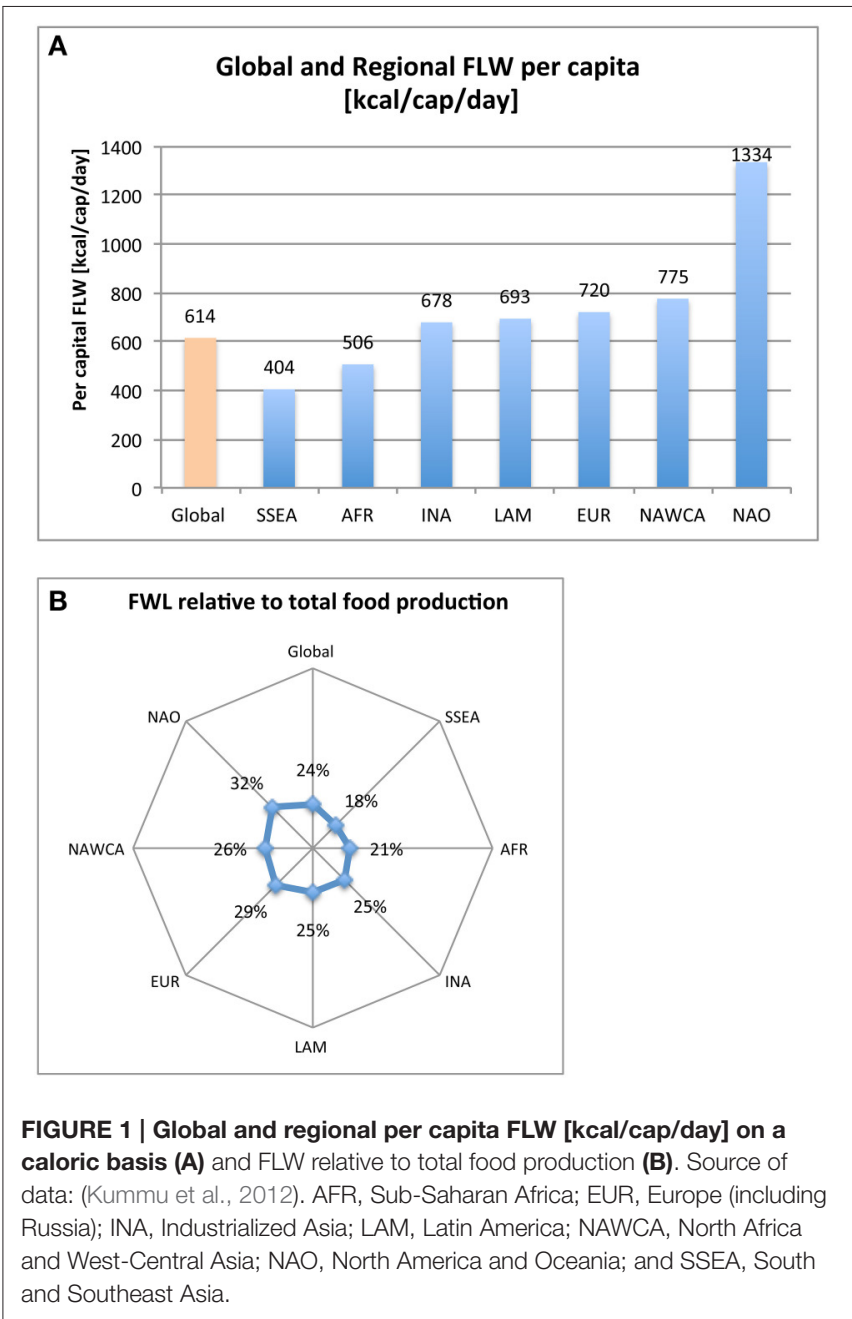


groundwater resources; Mekonnen and Hoekstra, 2010; Food and Agriculture Organization, 2013), with approximately $24 \%$ of total freshwater resources being used in food crop production (27 $\mathrm{m}^{3} /$ cap/year), and one-fifth of the fertilizers used for food crop production ( $4.3 \mathrm{~kg} / \mathrm{cap} /$ year). The amount of cropland used to grow this lost and wasted food is 198 million hectares per year (Kummu et al., 2012), which represents one-fifth of the cropland used globally for food crop production, or an area about the size of Mexico (Lipinski et al., 2013). A reduction of FLW will contribute to a decrease in land, water and nutrients use and in environmental externalities (Shafiee-Jood and Cai, 2016).

FLW also contributes to climate change, being responsible for an estimated $8 \%$ of global GHG emissions (Food and Agriculture Organization, 2015). In 2009 global FLW was responsible for roughly 3,300-5,600 million tons of carbon dioxide equivalent $\left(\mathrm{CO}_{2 \mathrm{e}}\right)$ [CGIAR (n.d.)]. GHG emissions resulting from global FLW are higher than any singular country in the world, except for China and the United States. Cereals make the greatest contribution to global FLW GHG emissions, at 34\%, followed by meat and vegetables ( $21 \%$ each) (Food and Agriculture Organization, 2013).

Natural landscapes and the ecosystem services they provide are also adversely affected by the resources that go into producing this lost and wasted food. Food and Agriculture Organization (2013) has assessed biodiversity impacts of FLW through the production phase for each commodity and region, highlighting their impacts due to related deforestation and to simplification and degradation of habitats (Phalan et al., 2013). Cereal production likely constitutes the main threat to biodiversity, especially around the tropics, in terms of deforestation and species' threats, in contrast to vegetable and fruit production, which have relatively less impact on biodiversity. Meat waste has overall higher environmental impacts in developing regions, although species threats due to livestock production represent only a third of those induced by agricultural crops (Food and Agriculture Organization, 2013).

Not all FLW has equal impact. The environmental impact of different FLW has been assessed in several studies (Kummu et al., 2012; Food and Agriculture Organization, 2013; Liu et al., 2013; Song et al., 2015) in terms of GHG emissions, land use, and water consumption per calorie, suggesting that reducing FLW should not be oriented only to those commodities with higher shares of caloric losses, but also paying attention to the overall impacts of each commodity (Shafiee-Jood and Cai, 2016).

According to Food and Agriculture Organization (2013), 33\% of the global FLW carbon footprint derives from products of animal origin, although their contribution to FLW volumes is only $15 \%$. The embedded GHG emissions of meat (poultry, bovine, goat, mutton, and swine) estimated by Porter et al. (2016), accounted for 34-38\% of all FLW production-phase GHG emissions, despite comprising just 3-4\% of total FLW by mass. Song et al. (2015) highlighted that although only 13\% of food wasted in China was animal derived foods, it accounted for $44 \%$ of the water embedded in total food waste. While vegetable and fruit production is a considerable source of food wastage with a large water footprint, it is likely to have relatively less important impacts on biodiversity than cereal production (Food and Agriculture Organization, 2013).
Finally, the global and regional trends have to be considered. Porter et al. (2016) have identified a 44\% increase in global average per capita FLW emissions between 1961 and 2011from $225 \mathrm{~kg}$ CO2e in 1961 to $323 \mathrm{~kg}$ CO2e in 2011. During that period, developing countries, particularly China and Latin American countries, produced the largest amount of GHG emissions associated with FLW, mainly from fruit and vegetable losses (Porter et al., 2016).

\section{SOCIOECONOMIC IMPACTS OF FLW}

According to the Food and Agriculture Organization (2015), around 800 million people do not have enough to eat. Decreasing FLW will contribute to reduce world hunger and improve food security (Neff et al., 2015; Kummu et al., 2016; ShafieeJood and Cai, 2016). It would also contribute to ensuring food safety and nutrition (Affognon et al., 2015; Neff et al., 2015), especially in developing countries where the highest number of people suffer from hunger and malnourishment (Food and Agriculture Organization, 2015). According to Food and Agriculture Organization (2014), the direct economic cost of 1.3 billion tons of FLW is around USD 1 trillion/year; which does not account for externalities, estimated at around USD 900 billion, and environmental costs and damages, estimated at around USD 700 billion.

FLW is also a significant economic loss when we account for the time invested in the production and supply chain, as well as in preparing the land, the use of fertilizers, and other costs caused by agricultural production (Bahadur et al., 2016; Kummu et al., 2016; Shafiee-Jood and Cai, 2016). For the United States, Buzby and Hyman (2012) estimated that in 2008, at the retail and consumer level, the total value of food loss at retail price was around USD165.5 billion. This is equivalent to around USD 390.00 per capita per year. The percentage of the top three food loss groups in terms of value were: $41 \%$ meat, poultry and fish; 17\% vegetables; and 14\% dairy products (Buzby and Hyman, 2012). In the case of the United Kingdom, for 20072008, the total cost of food and drink wasted was around USD 15 billion/year, which is equivalent to USD 598.00 at the household level per year (Waste and Resources Action Program, 2009).

FLW can also exacerbate poverty in developing countries. A decrease in the quality of the product will lead to a decrease in the quantity available to sell and consequently a decrease in economic gain (Affognon et al., 2015). Thus, FLW can decrease the income of small farmers and also increase food prices (due to low supply), which in turn will limit access to affordable food, particularly for lower-income individuals (Affognon et al., 2015; Shafiee-Jood and Cai, 2016). In SubSaharan Africa, for example, just a $1 \%$ reduction in postharvest losses could save $\$ 40$ million each year (World Bank, 2013).

However, other research suggests there is not currently enough information to understand in detail the socioeconomic impacts of FLW (Rutten, 2013; Bahadur et al., 2016; Chaboud and Benoit, 2017). Reliable and consistent data on food waste is difficult to find and comparison between regions and countries is a challenge. There is also debate as to the extent that investments to reduce FLW would outweigh the costs, which raises the 
question of how much "loss" could be accepted (Rutten, 2013; Bahadur et al., 2016; Chaboud and Benoit, 2017).

\section{ASSESSMENT OF POTENTIAL SOLUTIONS AND PRACTICES FOR PREVENTION AND MANAGEMENT OF FLW AT INTERNATIONAL LEVEL}

On a global scale, scientists and policy-makers continue to work toward FLW reduction strategies that address food waste at each stage of the FSC, adopting a sustainable production and consumption approach and most recently a circular economy approach. The implementation of these strategies must be adapted to the region, with particular consideration toward local infrastructure, energy, markets, and education (i.e., knowledge at all levels from supplier to consumer; Shafiee-Jood and Cai, 2016).

\section{Technological Solutions}

Food safety is the top priority in mitigating FLW; most technological solutions support the prevention of food contamination and quality degradation. Intervention at upstream stages benefits end-users; food safety is the main reason that American consumers report for FLW (Neff et al., 2015). Technological solutions include temperature-controlled storage (such as evaporative coolers) and/or improved, energyefficient refrigeration (HLPE, 2014; Koester, 2014; Bahadur et al., 2016) coupled with adequate storage, including metal silos and hermetic polythene bags (Lipinski et al., 2013; HLPE, 2014; Shafiee-Jood and Cai, 2016), as well as improved storage during transport, such as using tarps during grain transport and vented trucks for livestock and fresh food transport (Foscaches et al., 2012), and finally smart packaging (Olsmats and Wallteg, 2009; Pradeep et al., 2012; Lipinski et al., 2013). Improved infrastructure, specifically roads, is another technological priority (Choudhury, 2006; Food and Agriculture Organization, 2011) as are market structures and functions. Wholesale markets and/or marketing cooperatives can establish quality control and logistics mechanism (Kader, 2005; Food and Agriculture Organization, 2011; Koester, 2014; Radzevičius et al., 2015) and communication (specifically, enhanced technology for communication) along the FSC can inform decision-making and planning (Stuart, 2009; Bahadur et al., 2016).

\section{Cultural and Behavioral Solutions}

Reducing FLW at the individual consumer level in developed countries would create the biggest impact along the supply chain (Koester, 2014); one major point of education is improving understanding of "best before," "expires by," and "use by" dates on packaging (HLPE, 2014; Koester, 2014; Neff et al., 2015), coupled with retailers changing food date labeling practices (Lipinski et al., 2013). Other in-home practices, such as planned purchases, better storage practices, appropriate portion sizes, improved food preparation, and use of leftover food in meal preparation all reduce FLW (Quested et al., 2013). Retailers, restaurants and caterers can mitigate FLW by facilitating donations of unsold goods, implementing appropriate food portions, shifting in-store promotions to reduce potential unnecessary FLW (for example, "buy one, get one free later"), and through safe food storage practices (Lipinski et al., 2013; HLPE, 2014; Koester, 2014). Ultimately, education of individuals and groups at all levels of the FSC will lead to enhanced understanding of the complex factors contributing to FLW and increased likelihood of implementation of interventions at both upstream and downstream stages (Neff et al., 2015).

\section{Policy Solutions and recommendations}

Although this is an extremely important issue for decision makers, there are very few potential policy solutions and/or recommendations in the FLW literature (Rutten, 2013; Koester, 2014; Neff et al., 2015):

- The use of taxes and subsidies to decrease wasteful behavior among consumers;

- Financial support, especially in developing countries, to improve roads and energy infrastructure as well as the machinery used;

- Institutional arrangements and reforms to facilitate access of the private sector investment to agricultural production;

- Holistic approach/circular economy approach: focus on the causes of FLW as well as the consequences, regional and country differences; and the stakeholders and actors involved;

- Communication and education campaigns targeted to reduce food waste.

Some of the main challenges to policy development and implementation found were: inconsistencies in terminologies and definitions used; lack of reliable and consistent data; lack of applied research; lack of information on socioeconomic impacts; the need for monitoring and evaluation of existing policies; and the need for a holistic approach to address FLW (Rutten, 2013; Koester, 2014; Neff et al., 2015; Bahadur et al., 2016; Chaboud and Benoit, 2017).

\section{CONCLUSIONS}

There is a general consensus on the fact that reducing FLW has great potential for enhancing food security, strengthening sustainability of food systems and avoiding economic costs along the FSC, however there are substantial gaps in knowledge and research about FLW. Despite the scale of the problem, and according to the literature reviewed, lack of reliable and consistent data and inconsistences in definitions and measurement frameworks of FLW need to be addressed if FLW reduction strategies and solutions are to be effectively assessed and compared. Although this is an extremely important issue for decision makers, the review highlights the lack of information and evaluation on the socioeconomic impact of different measures and policies to reduce FLW in the literature. More holistic approaches should lead future research to tackle FLW as part of the circular economy, particularly on the socio-economic and environmental impacts of FLW reduction strategies across FSC stages in different regional and development contexts-considering, among others, infrastructure, energy, markets, and education. 


\section{AUTHOR CONTRIBUTIONS}

MV made substantial contributions to the conception and design of the work, the analysis and interpretation of data and drafting the manuscript. CF contributed in

\section{REFERENCES}

Affognon, H., Mutingi, C., Sanginpa, P., and Borgemeister, C. (2015). Unpacking postharvest losses in Sub-Saharan Africa: a meta-analysis. World Dev. 66, 49-68. doi: 10.1016/j.worlddev.2014.08.002

Bahadur, K., Haque, I., Legwegoh, A. F., and Fraser, E. D. (2016). Strategies to reduce food loss in the global South. Sustainability 8:595. doi: $10.3390 /$ su 8070595

Buzby, C. J., Bentley, T. J., Padera, B., Ammon, C., and Campuzano, J. (2015). Estimated Fresh Produce Shrink and Food Loss in U.S. Supermarkets. Agriculture 5, 626-648. doi: 10.3390/agriculture5030626

Buzby, J. C., and Hyman, J. (2012). Total and per capita value of food loss in the United States. Food Policy 37, 561-570.

Chaboud, G., and Benoit, D. (2017). Food losses and waste: navigating the inconsistencies. Global Food Sec. 12, 1-7. doi: 10.1016/j.gfs.2016.11.004

Choudhury, M. L. (2006). "Recent developments in reducing postharvest losses in the Asia-Pacific region," in Postharvest Management of Fruit and Vegetables in the Asia-Pacific Region, 15-22.

Food and Agriculture Organization (2011). Global Food Losses and Food WasteExtent, Causes and Prevention. Rome: FAO.

Food and Agriculture Organization (2013). Food Wastage Footprint: Impacts on Natural Resources. Rome: FAO.

Food and Agriculture Organization (2014). Food Wastage Footprint-Full-Cost Accounting - Final Report.Rome: FAO.

Food and Agriculture Organization. (2015). The State of Food Insecurity in the World. Rome: FAO.

Foscaches, C. A. L., Sproesser, R. L., Quevedo-Silva, F., and de Lima-Filho, D. O. (2012). Logística de frutas, legumes e verduras (FLV): um estudo sobre embalagem, armazenamento e transporte em pequenas cidades brasileiras. Informações Econômicas, 42, 37-46. Available online at: http://www.iea.sp.gov. br/ftpiea/publicacoes/IE/2012/tec4-03-04-2012.pdf

Gustavsson, J., Cederberg, C., Sonesson, U., van Otterdijk, R., and Meybeck, A., (2011). A. Global Food Losses and Food Waste: Extent, Causes, and Prevention. Rome: Food and Agricultural Organization.

Hanson, C., Lipinski, B., Robertson, K., Dias, D., Gavilan, I., Gréverath, P. et al. (2016). Food Loss and Waste Accounting and Reporting Standard. WRI, Nestlé, CGF, FAO, EU-funded FUSIONS project, UNEP, WRAP, WBCSD, NRI.

HLPE (2014). Food Losses and Waste in the Context of Sustainable Food Systems. A report by the High Level Panel of Experts on Food Security and Nutrition of the Committee on World Food Security, Rome.

Kader, A. A. (2005). "Increasing food availability by reducing postharvest losses of fresh produce," in Proceedings of 5th International Postharvest Symposium Acta Horticulturae 682 (Davis, CA: ISHS).

Koester, U. (2014). Food loss and waste as an economic and policy problem. Intereconomics 6, 348-354. doi: 10.1007/s10272-014-0518-7

Kummu, M., de Moel, H., Porkka, M., Siebert, S., Varis, O., and Ward, P. J. (2012). Lost food, Wasted Resources: Global Food Supply Chain Losses and Their Impacts on Freshwater, Cropland, and Fertiliser Use. Sci. Total Environ. 438, 477-489. doi: 10.1016/j.scitotenv.2012.08.092

Kummu, M., Guillaume, J. H. A., de Moel, H., Eisner, S., Flörke, M., Porkka, M., et al. (2016). The world's road to water scarcity: shortage and stress in the 20th century and pathways towards sustainability. Sci. Report 6:38495. doi: $10.1038 /$ srep 38495

Lipinski, B., Hanson, C., Lomax, J., Kitinoja, L., Waite, R., and Searchinger, T. (2013). Reducing Food Loss and Waste: Working Paper. Washington, DC: World Resources Institute.

Liu, J. G., Lundqvist, J., Weinberg, J., and Gustafsson, J. (2013). Food Losses and Waste in China and their implication for water and land. Environ. Sci. Technol. 47, 10137-10144. doi: 10.1021/es401426b the acquisition and interpretation of data, drafting the manuscript and revising the work critically. CQ contributed to the conception of the work, the analysis of data and drafting of the manuscript. All authors accepted the final version.

Mekonnen, M. M., and Hoekstra, A. Y. (2010). The green, blue and grey water footprint of crops and derived crop products. Value of Water Research Report Series No. 48. Delft: UNESCO-IHE. Available online at: http://wfn.projectplatforms.com/Reports/Report47-WaterFootprintCrops-Vol1.pdf

Neff, R., Kanter, R., and Vandevijvere, S. (2015). Reducing food loss and waste while improving the public's health. Health Affairs 34, 1821-1829. doi: 10.1377/hlthaff.2015.0647

Olsmats, C., and Wallteg, B. (2009). Packaging is the Answer to World Hunger. World Packaging Organisation (WPO) and International Packaging Press Organisation (IPPO). Available online at: http://www.worldpackaging.org/i4a/pages/index.cfm?pageid=1\#\&panel1-1

Parfitt, J., Barthel, M., and Macnaughton, S. (2010). Food waste within food supply chains: quantification and potential for change to 2050. Philos. Trans. R. Soc. B 365, 3065-3081. doi: 10.1098/rstb.2010.0126

Phalan, B., Bertzky, M., Butchart, S. H. M., Donald, P. F., Scharlemann, J. P. W., Stattersfield, A. J., et al. (2013). Crop expansion and conservation priorities in tropical countries. PLOS ONE 8:e51759. doi: 10.1371/journal.pone.00 51759

Porter, S., Reay, D., Higgins, P., and Bomberg, E. (2016). A half-century of production-phase greenhouse gas emissions from food loss \& waste in the global food supply chain. Sci. Total Environ. 571, 721-729. doi: 10.1016/j.scitotenv.2016.07.041

Pradeep, P., Junho, J., and Sanghoon, K. (2012). Carbon dioxide sensors for intelligent food packaging applications. Food Control 25, 328-333. doi: 10.1016/j.foodcont.2011.10.043

Quested, T. E., Marsh, E., Stunell, D., and Parry, A. D. (2013). Spaghetti soup: the complex world of food waste behaviour. Res. Conserv. Recycl. 79, 43-51. doi: 10.1016/j.resconrec.2013.04.011

Radzevičius, G., Ramanauskas, J., and Contò, F. (2015). Possibilities for reduction of food loss and waste: the case study of Lithuania's producer cooperatives. Italian J. Food Sci. 99-102

Rutten, M. (2013). What economic theory tells us about the impacts of reducing food losses and/or waste: implications for research, policy, and practice. Agric. Food Sec. 2:13. doi: 10.1186/2048-7010-2-13

Shafiee-Jood, M., and Cai, X. (2016). Reducing food loss and waste to enhance food security and environmental sustainability. Environ. Sci. Technol. 50, 8432-8443. doi: 10.1021/acs.est.6b01993

Song, G., Li, M., Semakula, H. M., and Zhang, S. (2015). Food consumption and waste and the embedded carbon, water and ecological footprints of households in China. Sci. Total Environ. 529, 191-197. doi: 10.1016/j.scitotenv.2015. 05.068

Stuart, T. (2009). Waste - Uncovering the Global Food Scandal. London: Penguin Books.

Waste and Resources Action Program (WRAP) (2009). Household Food and Drink Waste in the UK. Banbury: Waste and Resources Action Program.

World Bank (2013). Food Wastage Footprint Impacts on Natural Resource. Food and Agriculture Organization of the United Nations. Editor: Nadia El-Hage Scialabba. Report No. 60371-AFR.

Conflict of Interest Statement: The authors declare that the research was conducted in the absence of any commercial or financial relationships that could be construed as a potential conflict of interest.

Copyright (C) 2017 Vilariño, Franco and Quarrington. This is an open-access article distributed under the terms of the Creative Commons Attribution License (CC BY). The use, distribution or reproduction in other forums is permitted, provided the original author(s) or licensor are credited and that the original publication in this journal is cited, in accordance with accepted academic practice. No use, distribution or reproduction is permitted which does not comply with these terms. 